\title{
Goldenhar syndrome and overlapping dysplasias, in vitro fertilisation and ovopathy
}

SUMmARY In contrast to the opinion of Yovich et al, ${ }^{1}$ who documented Goldenhar syndrome in one of possibly monozygous twin brothers conceived by in vitro fertilisation and embryo transfer, $\vec{\circ}$ I suggest that ovopathy is the cause of this anomaly. The eight criteria which have to be metos before a condition can be said to be caused by overripeness ovopathy are shown to be $\vec{\sigma}$

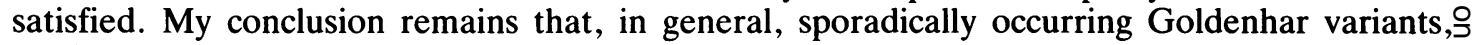
as distinct from familial cases, should be considered to be just casualties in the broad 'continuum of reproductive wastage' seen in high risk conceptions, one of which is IVF. This concept increases our understanding of human variation not satisfactorily explained by Mendelian?응 inheritance.

The Goldenhar syndrome ${ }^{2}$ (GS) and its variants, also referred to as the Goldenhar anomalad or the oculoauriculovertebral (OAV) dysplasias, occupy a central position in the broad spectrum of overlapping anomalies related to the eyes, ears, face, and vertebral column. GS was the first congenital anomaly presumed to be caused by overripeness ovopathy in humans. ${ }^{3}{ }^{4}$ This hypothesis, proposed in 1968, was built up on the following.

(1) Case studies, including the documented history of a proband, a sixth child, conceived despite the use of the rhythm method of contraception on the 30th day of a prolonged menstrual cycle during the post-partum restoration of the ovulatory pattern.

(2) The clear parallels with the deficiencies in tissue differentiation and organogenesis found in animals after preovulatory ${ }^{5}$ and postovulatory ${ }^{6}$ ageing of the egg, often leading to concordant and more specifically to discordant monozygous (MZ) twins.

(3) The numerous and fluent transitions to other syndromes and congenital dysplasias, such as hemifacial microsomia, asymmetrical crying face with congenital eye defects, Duane retraction syndrome, Wildervanck syndrome, KlippelFeil anomaly, and many others, that often can not be distinguished diagnostically.
(4) The mainly sporadic occurrence which is diffi cult to reconcile with Mendelian inheritance.

(5) The wide variation of associated anomalies. This line of thought has been substantiated byo both a retrospective and a prcspective study show $\bar{D}$ ing that the (preovulatory) hypothermic phase of the conceptional cycle is longer and that the tempera응 ture rise is slower in mothers of infants with congenital dysplasias (for example, of the face) than in those of normal term infants. ${ }^{78}$ In fact, cases of OAV dysplasias have been reported in singletons as well as in concordant or discordant $\mathrm{MZ}$ twins, irb which gametopathy has been, or should be, consi 3 . dered as the presumed cause due to a non-optimung conception, as will be seen later.

Therefore, it is not just a strange coincidence that GS is also the first congenital anomaly reported following in vitro fertilisation (IVF) and embryoo transfer (ET), even though any causal relationship: was denied either with the method of conception on with possible $\mathrm{MZ}$ twinning. ${ }^{1}$ This treatment was carried out because of infertility due to polycystiq ovary disease, and it resulted in male triplets. One $e^{\omega}$ of these was affected by GS but a possibly MZ twin brother was not $(p<0.001$ for dizygosity, except fof the Fy(a) antigen).

In the present paper I contest the statements of Yovich et $a^{1}$ that this anomaly is not causally related either to (possibly) MZ twinning or to the techni ques applied (IVF and ET). After all, many MZP twins have been reported after IVF $^{9}$ and discord $\stackrel{\rho}{=}$ 
ance is a striking phenomenon in GS. ${ }^{10-12}$ In addition, increased fetal loss, abnormal embryonic development, and some degree of microphthalmia have been reported in nearly half of the offspring after IVF in rats ${ }^{13}$; there is also a $90 \%$ failure rate of implantation of human IVF embryos, a $30 \%$ abortion rate, and a high rate of chromosomal abnormalities in preimplantation embryos. ${ }^{14}{ }^{15}$ In fact, the follicular fluid of endocrinologically normal women has been shown to contain more inhibin activity and lower oestrogen and progesterone levels when stimulated than-when not. ${ }^{16}$ Superovulation therapy, of course, 'forces' the development of a spectrum of preovulatory oocytes which are in different phases of maturation at the moment that the human chorionic gonadotrophin (HCG) dose is given; if the timing is optimal for some, it will be too late or too early for others and so eggs less likely to undergo further normal development will be produced ${ }^{17}$ It is true that no increase in congenital anomalies and chromosomal aberrations above that found after conceptions in vivo has been observed, and no constant pattern of anomalies has emerged suggesting a specific underlying defect in the treatment, ${ }^{9}$ but comparison of the outcome of pregnancy after IVF with the outcome after in vivo conceptions at high risk ${ }^{18}$ may be informative about fundamental aspects of developmental processes and tissue disruption.

Although the necessary epidemiological data on OAV dysplasias and Goldenhar variants are not always available, additional support for overripeness ovopathy being the cause has been found in more recent published reports. ${ }^{19} \mathrm{I}$ will show this by means of the eight criteria that have been deduced from animal ageing egg research which have to be satisfied to substantiate this aetiology.

\section{The overripeness ovopathy theory}

In both animals and humans, delay of either ovulation or fertilișation leads to meiotic (and mitotic) non-disjunction and also to failed cell interaction, impeded morphogenetic movements, tissue disruption, and altered differentiation schedules. This results in embryonic or fetal death, growth retardation, differential growth, changes in the respective positions of cells shaping the organs and the body, that is, dysplasias of one or more developmental fields (polymorphic syndromes), or functional deficits in the neonate, infant, or even adult. This constitutes a clear and recognised 'continuum of reproductive casualties'. 782021 This disturbance starts from the ovum and induces a slow down of the rapid, sequential, and considerable growth in one or more developmental fields instead of at one or another critical stage of embryonic or fetal development, as is generally believed in the case of developmental anomalies. Either ovulation may be delayed during the transitional stages of reproductive life (adolescence, premenopause, postpartum, weaning, 'ovulatory' and 'anovulatory' seasons), or fertilisation may occur in the case of inconsistent and ineffective contraception. ${ }^{1822}$

\section{The overripeness ovopathy criteria}

\section{(1) SPORADIC OCCURRENCE}

That occurrence of OAV dysplasias or the Goldenhar variants is mainly sporadic is generally agreed. ${ }^{23}$ It is true that in some instances of limbal dermoids and of first and second branchial arch syndromes meticulous family studies have disclosed signs in relatives, pointing to recessive and dominant genetic factors. ${ }^{24-27}$ It should be pointed out that a maternal constitution may predispose to recurrent ovopathy and to mimicry of Mendelian inheritance, ${ }^{18}$ but familial cases often look like 'pseudo-OAV', dysplasias caused by mutant alleles (genocopies), which are difficult to distinguish, particularly when the clinical signs are less marked and less typical. ${ }^{28}$ In every case, two clearly autosomal dominant disorders emerge from the 'hereditary ear adysplasia-renal dysplasia syndrome', namely branchio-oto-renal (BOR) dysplasia and branchiooto (BO) dysplasia. ${ }^{24-27}$ These genocopies, of course, should be separated from the Goldenhar dysplasias caused by overripeness ovopathy.

\section{(2) CONCORDANT AND DISCORDANT} OCCURRENCE IN MZ TWINS

As in the animal experiments on delayed ovulation (preovulatory overripeness ovopathy ${ }^{5}$ ) and delayed fertilisation (postovulatory overripeness ovopathy ${ }^{6}$ ), OAV dysplasias have been noticed frequently in both concordant and discordant $\mathrm{MZ}$ twins. ${ }^{4}{ }^{10-12}$ Therefore, the denial of Yovich et al ${ }^{1}$ of a causal relationship between MZ twinning and OAV dysplasia, albeit an indirect one, is hard to substantiate. In fact, an increased incidence of identical twins has been presumed after IVF $^{9}$ and the increase of early embryonic malformations and developmental field complexes such as GS in one or both MZ twins has been the stimulus for considering a common aetiology for both $M Z$ twinning and the early malformation problem. ${ }^{11}$ Overripeness ovopathy could lead to one or the other ${ }^{4} 19$ and therefore GS after IVF $^{1}$ may be considered as just a casualty in the broad 'continuum of reproductive wastage' also seen in other high risk conceptions. ${ }^{18}$ 
(3) ACCOMPANIMENT OF MULTIPLE CONGENITAL ANOMALIES

As in the animal experiments on ageing of the egg, a wide spectrum of associated anomalies, not restricted to the derivatives of the primordia for the eyes, first and second branchial arch structures, or notochord, have been reported in OAV dysplasias. ${ }^{23}$ Central nervous system anomalies in all their varieties often accompany the OAV dysplasias or the so-called maxillomandibular neurocristopathies ${ }^{28}$ for example, hypoplasia or aplasia of one or more nuclei in the brain stem and their corresponding cranial nerves with sensory, sensorineural, and motor deficiencies. ${ }^{29}$ The same is true for cardiovascular, pulmonary, renal, visceral, and skeletal dysplasias (oral clefts, polydactyly), etc. $^{23} 2931$ These associated anomalies and their severity do not appear to follow a specific distribution, as would be expected if genetically determined, but rather the casual distribution in the general population. ${ }^{32}$ The unwieldy nature of these malformations appears to be dependent on the disruption in one or more developmental fields and also explains the overlap with the CHARGE association, ${ }^{33}$ the MURCS association, ${ }^{34}$ the immunodeficiencies, ${ }^{35}$ idiopathic hypoparathyroidism and thymic dysplasia (DiGeorge syndrome ${ }^{36}$ or branchial dysembryogenesis ${ }^{37}$ ), and many other defects. Therefore, each one of the infinite number of possible variations either assumes an eponym or is classified with the first and second branchial arch malformations, a spectrum of dysplasias in which anomalies of the eyes, ears, face, and vertebral column appear to be markers rather than obligatory parts of them. ${ }^{38}{ }^{39}$ This complex group of patients of course "do not necessarily represent formal genesis syndromes or nosologic entities different from the other types"31 36 and introduction of the overripeness ovopathy theory here supports the 'lumping' rather than the 'splitting' attitude.

(4) ACCOMPANIMENT OF NON-SPECIFIC

CHROMOSOMAL ABERRATIONS

As in dysplastic fetuses resulting from experimental ageing of the egg in animals, ${ }^{21}$ subjects affected by OAV dysplasias are sometimes found to have nonspecific chromosomal aberrations, for example, $47, X X X^{40} \quad 49, X^{40 X X},{ }^{41} \quad 46, X X / 47, X X,+7$ mosaicism, ${ }^{42} 47, \mathrm{XXY}, 49, \mathrm{XXXXY}, 46, \mathrm{Bp}-($ twice), $46,18 q-$, and other structural defects. ${ }^{27}$

(5) ACCOMPANIMENT OF GONADAL

DYSGENESIS

In animal ovopathy experiments, ${ }^{6}$ the primordial germ cells exhibit degenerative features even when only slightly affected by the ageing process. They multiply slowly and enter the gonadal folds only i small numbers or not at all and this results if dysgenesis of the gonads. Although few researchers have payed attention to this area, cryptorchidism ovarian anomalies, and other genital malformation have occasionally been mentioned in this comples group of Goldenhar variants. ${ }^{33} 344344$ Unimpaireकै fertility has been claimed for GS in a "natural history" of the disorder ${ }^{45}$ but this conclusion is questionable as it was based on 24 patients of when only two were adults, a female of 37 and a male of 58 years? without any data concerning their reproductive performance.

(6) ASSOCIATION OF SUBOPTIMAL REPRODUCTIVESTATE OF THE PROBAND'S MOTHER

Subjects with OAV dysplasias born to mothers with casual or constitutional impairment of the ovulatory pattern or difficulty in conceiving have bee® reported. ${ }^{146}$ In spina bifida cystica and occultof nearly half of the mothers appear to have beeक reported to have had a history of irregular cycles, long periods of infertility, menorrhagia, and severs dysmenorrhoea, and some showed an increased rate of abortion, stillbirths, and even recurrent neurat tube defects. ${ }^{47}$ The same suboptimal reproductive state has been established in mothers of oral clef children. ${ }^{48}$

(7) ASSOCIATION WITH HIGH RISK CONCEPTIONS

There are case reports of OAV dysplasias in whic other non-optimum conceptions are presumed, fo example, where an insulin dependent diabeti\&. mother is concerned, ${ }^{4950}$ when conception has taken place during use or immediately after stopping the contraceptive pill, ${ }^{36425152}$ or otherwise un planned pregnancies. ${ }^{3}{ }^{51}$ This is in line with the over ripeness ovopathy predictions, as are also the pro@ longed preovulatory phase and the slower tempera ture rise in the conceptional cycle of mothers of infant? with congenital dysplasias (particularly of the face compared with those of normal term infants. ${ }^{78}$

(8) ASSOCIATION WITH VARIOUS COMPLICATIONS OF PREGNANCY, PARTURITIOM AND NEONATAL LIFE

Among the complications commonly reported ib OAV dysplasias, evidently the very early ones, suck as ectopic pregnancies (tubal pregnancies and placenta praevia), MZ twinning, and vaginal bleede ing in very early pregnancy, are narrowly related to the early condition of the fertilised egg and predate the formation of the relevant facial and vertebra structures in a three to five week embryo. There $\frac{\overrightarrow{\mathrm{D}}}{\mathrm{D}}$ fore, a reconstruction of the cause and effect mag 
show ovopathy to be the primordial insult and the common cause of both dysmorphogenesis and complications in early as well as late pregnancy and the neonatal period.

\section{Conclusions}

The arguments of Yovich et al ${ }^{1}$ that the condition in their proband with GS is not causally related either to (possibly) MZ twinning or to IVF remain speculative. MZ twinning has been reported frequently after IVF and in connection with Goldenhar dysplasia. In addition, GS also shows the same tendency to discordant $\mathrm{MZ}$ twinning and to disruption in the developmental fields of the primordial eyes, branchial arch structures, and notochord, as shown by experimental animal research on ageing ova. GS also satisfies the eight criteria which have to be met before a condition can be said to be caused by overripeness ovopathy. The casual association with non-specific chromosomal aberrations and with (discordant) $\mathrm{MZ}$ twinning explicitly dates the timing and type of insult, assigning it to the meiotic and first mitotic divisions instead of to the third to fifth week of pregnancy as is usually thought. Therefore, I maintain that the (mainly) sporadic OAV dysplasias, as distinct from the (mainly) familial cases which are genetically determined, should be considered as casualties in the broad 'continuum of reproductive wastage' seen after high risk conceptions, one of which is IVF.

P H JONGbLet
'Maria Roepaan',
Centre for the Mentally Handicapped,
6595 NX Ottersum; and Institute of Human Genetics,
Free University,
1081 BT Amsterdam,
The Netherlands.

\section{References}

1 Yovich JL, Stanger JD, Grauaug AA, Lunay GG, Dawkins RL, Mulcahy MT. Fetal abnormality (Goldenhar syndrome) occurring in one of triplet infants derived from in vitro fertilization with possible monozygotic twinning. $J$ In Vitro Fert Embryo Trans 1985;2:27-32.

2 Goldenhar M. Associations malformatives de l'ocil et de l'oreille. J Genet Hum 1952;1:243-82.

3 Jongbloet PH. Considerations on the aetiology of Goldenhar's syndrome and related congenital dysplasias including chromosomal aberrations. Maandschr Kindergeneeskd 1968;36:352-67.

4 Jongbloet PH. Monozygotic twinning, structural defects, and syndromes 'of obscure etiology'. J Pediatr 1980;97:868-9.

5 Mikamo K. Intrafollicular overripeness and teratologic development. Cytogenetics 1968;7:212-33.

6 Witschi E. Overripeness of the egg as a cause of twinning and teratogenesis. Cancer Res 1952;12:763-8.

7 Spira A, Spira N, Papiernik-Berkhauer E, Schwartz D. Pattern of menstrual cycles and incidence of congenital malformations. Early Hum Dev 1985;11:317-24.
8 Troya M, Bomsel-Helmreich O, Bertrand P, Papiernik E, Spira A. Relationship between the characteristics of the menstrual cycle and congenital malformations in the human. Early Hum Dev 1985;11:307-15.

9 Edwards RG. The current situation of in-vitro fertilization. IPPF Medical Bulletin 1984;18:1-2.

10 Burck U. Genetic aspects of hemifacial microsomia. Hum Genet $1983 ; 64: 291-6$

" Schinzel AAGL, Smith DW, Miller JR. Monozygotic twinning and structural defects. J Pediatr 1979;95:921-30.

12 Stoll C, Roth MP, Dott B, Bigel P. Discordance for skeletal and cardiac defect in monozygotic twins. Acta Genet Med Gemellol (Roma) 1984;33:501-4.

13 Niwa K, Iritani A. Possible occurrence of embryonic abnormalities from artificial insemination and fertilization in vitro. Teratology 1980;22:4A.

${ }^{14}$ Spielmann H, Krüger C, Stauber M, Vogel R. Abnormal chromosome behavior in human oocytes which remained unfertilized during human in vitro fertilization. J In Vitro Fert Embryo Trans 1985;2:138-42.

is Angell RR, Templeton AA, Aitken RJ. Chromosome studies in human in vitro fertilization. Hum Genet 1986;72:333-9.

16 Channing CP, Tababe K, Seegar Jones G, Jones HW, Lebech P. Inhibin activity of preovulatory follicles of gonadotropin-treated and untreated women. Fertil Steril 1984;42:243-8.

${ }_{17}$ Hillier SG, Siddiquey AKS, Winston RML. Fertilization in vitro of cumulus-enclosed mouse oocytes: effect of timing of the ovulatory HCG injection. Int J Fertil 1985;30:34-8.

18 Jongbloet PH. Background biological effects. In: Chamberlain G, Lumley J, eds. Prepregnancy care: a manual for practice. London: Wiley, 1986:39-52.

19 Jongbloet PH. Diagnostic criteria for overripeness ovopathy. Maandschr Kindergeneeskd 1971;39:251-80.

20) Iffy L. Ovulation defects and ovum pathology. In: Iffy L, Kaminetzky HA, eds. Principles and practice of obstetrics and perinatology. New York: Wiley, 1981:323-38.

21 Butcher RL. Experimentally induced gametopathies. In: Iffy L, Kaminetzky HA, eds. Principles and practice of obstetrics and perinatology. New York: Wiley, 1981:339-49.

22 Jongbloet PH. The ageing gamete in relation to birth control failures and Down syndrome. Eur J Pediatr 1985;144:343-7.

${ }^{23}$ Gorlin RJ, Pindborg JJ, Cohen MM. Syndromes of the head and neck. 2nd ed. New York: McGraw-Hill, 1976:546-52.

${ }^{24}$ Karmody CS, Feingold M. Autosomal dominant first and second branchial arch syndrome. A new inherited syndrome? In: Bergsma D, ed. Malformation syndromes. Birth Defects. Vol X. New York: The National Foundation-March of Dimes, 1974:31-40.

${ }^{25}$ Melnick M, Hodes ME, Nance WE, Yune H, Sweeney $A$. Branchio-oto-renal dysplasia and branchio-oto dysplasia: two distinct autosomal dominant disorders. Clin Genet 1978;13:42542.

${ }^{26}$ Regenbogen L, Godel V, Goya V, Goodman RM. Further evidence for an autosomal dominant form of oculoauriculovertebral dysplasia. Clin Genet 1982;21:161-7.

${ }^{27}$ Rollnick BR, Kaye CI. Hemifacial microsomia and variants: pedigree data. Am J Med Genet 1983;15:233-53.

${ }^{28}$ Couly G, Le Lièvre-Ayer C. Malformations latero-faciales (neurocristopathies maxillo-mandibulaires) associées à des anomalies du tronc cerebral et des nerfs craniens. Rev Stomatol Chir Maxillofac 1983;84:254-63.

${ }^{29}$ Aleksic S, Budzilovich G, Greco MA, McCarthy MA, Reuben J, Margolis S. Intracranial lipomas, hydrocephalus and other CNS anomalies in oculoauriculo-vertebral dysplasias (Goldenhar-Gorlin syndrome). Child's Brain 1984;11:285-97.

30 Opitz J, Faith GS. Visceral anomalies in an infant with the Goldenhar syndrome. In: Bergsma D, ed. Proc 1st Conf on Clin Delineation of Birth Defects. Part II. Malformation syndromes. 
Birth Defects Vol V. New York: The National Foundation-

March of Dimes, 1969:104-5.

31 Cohen MM. Variability versus 'incidental findings' in the first and second branchial syndrome: unilateral variants with anophthalmia. Birth Defects 1971;7:103-8.

${ }^{32}$ Friedman S, Saraclar M. The high frequency of congenital heart disease in oculo-auriculo-vertebral dysplasia (Goldenhar's syndrome). J Pediatr 1974;85:873-4.

${ }^{33}$ Siebert JR, Graham JM, MacDonald C. Pathological features of the CHARGE association: support for involvement of the neural crest. Teratology 1985;31:331-6.

${ }^{34}$ Duncan PA, Shapiro LR, Stangel JJ, Klein RM, Addonizio JC. The MURCS association: Müllerian duct aplasia, renal aplasia, and cervicothoracic somite dysplasia. J Pediatr 1979;95:399-402.

${ }^{35}$ Say B, Miller GC, Barber N, Grogg S. Association of birth defects and immunodeficiency. J Pediatr 1979;94:849.

36 Blank E. A cardio-facial-skeletal syndrome. AJR 1972;116:634 9.

37 Miller MJ, Frame B, Poznanski AK, Jackson CE, Bermudez G. Branchial anomalies in idiopathic hypoparathyroidism: branchial dysembryogenesis. Henry Ford Hosp Med J 1972;20:3-14.

${ }^{38}$ Black FO, Yers EN, Rorke LB. Aplasia of the first and second branchial arches. Arch Otolaryngol 1973;98:124-8.

${ }^{39}$ Miller MT. Association of Duane retraction syndrome with craniofacial malformations. J Craniofac Genet Dev Biol 1985; suppl 1:273-82.

40) Aouchiche M, Boyer R, Nouar A. Results of karyotype analysis in Goldenhar's syndrome. Bull Soc Ophtalmol Fr 1972;85:57-69.

${ }^{41}$ Schroeter C, Jahrig K, Weinke I. Ein neuer fall von pentasomie X. Helv Paediatr Acta 1980;35:233-41.

42 Hodes ME, Gleiser G, Paul DeRosa G, et al. Trisomy 7 mosaicism and manifestations of Goldenhar syndrome with unilateral radial hypoplasia. J Craniofac Genet Dev Biol 1981;1:49-55.

${ }^{43}$ Schwartzenberg T, Vancea PP, Scântei V, Covic M. Problèmes de diagnostic et de traitement dans un cas clinique de dysplaste oculo-auriculaire associée à la dysostose mandibulo-faciafe (syndrome de Franceschetti-Goldenhar). Ophthalmologig 1978;177:1-12.

44 Winer-Muram HT, Muram D, Wilroy RS, Cupp C. T底 concurrence of facioauriculovertebral spectrum and the Rok tansky syndrome. Am J Obstet Gynecol 1984;149:569-70. ¿

45 Shokeir MHK. The Goldenhar syndrome: a natural histonge Birth Defects 1977;13(3C):67-83.

46 Ter Haar B. Oculo-auriculo-vertebral dysplasia (Goldenha $\overrightarrow{\mathbf{C}^{3}}$ syndrome) concordant in identical twins. Acta Genet Med Gemellol (Roma) 1972;21:116-24.

47 Wynne-Davies R. Congenital vertebral anomalies: aetiologg and relationship to spina bifida cystica. J Med Gent? 1975;12:280-8.

${ }^{48}$ Jongbloet PH. Birth intervals in oral cleft families. Clin Gerier 1984;26:488-94.

49 Gratz ES, Pollack MA, Zimmerman RD. Congenital faci记 palsy and ipsilateral deafness: association with maternal dif abetes mellitus. Int J Pediatr Otorhinolaryngol 1981;3:335-41

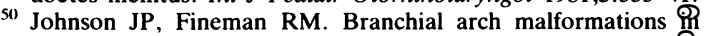
infants of diabetic mothers: two case reports and a review. Am Med Genet 1982;13:125-30.

51 Papp Z, Gardo S, Walawska J. Probably monozygotic twins with discordance for Goldenhar syndrome. Clin Genet 1974;5:86-90.

52 Papp Z, Gardo S, Dolhay B, Ruzicska GY. Indirect effect of se hormones on the fetus. J Pediatr 1976;88:524.

Correspondence and requests for reprints to $\operatorname{Dr} P \overrightarrow{\mathrm{g}}$ Jongbloet, 'Maria Roepaan', Siebengewaldsewęg 15, 6595 NX Ottersum, The Netherlands.

This paper was shown to Dr Yovich and colleague who reply on page 644 . 